\title{
Evolution of resident bird breeding phenology in a landscape with heterogeneous resource phenology and carryover effects
}

\author{
Nadiah Pardede Kristensen ${ }^{1,3}$ (D) . Jacob Johansson ${ }^{1} \cdot$ Niclas Jonzén ${ }^{1}$. \\ Henrik G. Smith ${ }^{1,2}$
}

Received: 6 March 2018 / Accepted: 20 August 2018 / Published online: 31 August 2018

(C) The Author(s) 2018

\begin{abstract}
It is generally expected that, in environments with pronounced seasonal resource peaks, birds' reproductive success will be maximised when nestlings' peak food demand coincides with the timing of high food availability. However in certain birds that stay resident over winter, earlier breeding leads juveniles to join the winter flock earlier, which by the prior residence effect increases their success in breeding territory competition. This tradeoff between reproduction and competition may explain why, in certain species, breeding phenology is earlier and asynchronous with the resource. This study extends a previous model of the evolution of breeding phenology in a single habitat type to a landscape with two habitat types: 'early' and 'late' resource phenology. The offspring's natal habitat type has a carryover effect upon their competitive ability regardless of which habitat type they settle in to potentially breed. We find that, when the difference in resource phenology between habitats is small (weak carryover effect), breeding phenology in the late habitat evolves to occur earlier and more asynchronously than in the early habitat, to compensate for the competitive disadvantage to juveniles raised there. However if the difference is large (strong carryover effect), then the reproductive cost of earlier breeding outweighs the benefit of the compensation, so instead breeding phenology in the late habitat evolves to become more synchronous with the resource. Recruitment is generally asymmetric, from early to late habitat type. However if the early habitat is less frequent in the landscape or produces fewer offspring, then the asymmetry is reduced, and if there is some natal habitattype fidelity, then recruitment can have an insular pattern, i.e. most recruits to each habitat type come from that same habitat type. We detail the different scenarios in which the different recruitment patterns are predicted, and we propose that they have implications for local adaptation.
\end{abstract}

Keywords Adaptive dynamics · Dominance hierarchy · Parids · Phenological mismatch · Source-sink · Isolation by ecology

Electronic supplementary material The online version of this article (https://doi.org/10.1007/s1068 2-018-9951-6) contains supplementary material, which is available to authorized users.

Nadiah Pardede Kristensen nadiah@nadiah.org

Extended author information available on the last page of the article 


\section{Introduction}

A fundamental aspect of life-history evolution is phenology, which is the timing of key recurring biological events. Synchrony in phenology between a species and its resource has been the focus of much research, for example the match/mismatch in the timing between nestlings' peak food demand and the peak in food abundance (Visser and Both 2005; Vatka et al. 2016). All else being equal, the importance of provisioning offspring with food suggests that breeding phenology should be synchronised with resource phenology (Johansson et al. 2015). However breeding phenology also influences and is influenced by selection on processes at other stages of the life cycle, notably the competitive processes leading up to the breeding stage (Jonzén et al. 2007; Johansson et al. 2012).

The effect of breeding phenology on juveniles' competitive success at later life stages (e.g. Arcese and Smith 1985; Desrochers et al. 1988) may explain why some winter-resident birds breed before synchrony with the resource peak. Breeding date influences the timing of natal dispersal, which in turn influences arrival date of juveniles to the winter flock, and in resident species such as parids, earlier arrival to the winter flock can give juveniles a competitive advantage in breeding-territory competition (Nilsson and Smith 1988; Nilsson 1990; Koivula et al. 1993). Therefore we expect synchrony between breeding and resource timing to be traded against juvenile competitive ability, resulting in asynchrony between breeding and resource (Johansson et al. 2014). This mechanism may be part of the explanation for why the breeding phenology in some populations of willow tits (Poecile montanus) (Vatka et al. 2011), coal tits (Parus ater) (Both et al. 2009), and marsh tits (Poecile palustris) (Wesołowski 1998) is early and asynchronous with the caterpillar peak.

A landscape is likely to consist of a mix of habitat types with different resource phenologies, which raises the possibility that landscape composition will influence interhabitat recruitment dynamics and selection on breeding date. For example, deciduous forests have an earlier caterpillar phenology than evergreen forests (Veen et al. 2010), and this constrains the breeding phenology of birds that can successfully breed within them (Blondel et al. 1993; Lambrechts et al. 1997). Given that resource phenology influences breeding phenology which in turn influences competitive ability (e.g. Arcese and Smith 1985; Desrochers et al. 1988), we would therefore expect that juveniles raised in evergreen forest patches will be competitively disadvantaged in breeding-territory contests against juveniles raised in deciduous forest patches (Johansson et al. 2014). How the breeding phenology in the different habitat types evolves in response to these carryover effects (sensu O'Connor et al. 2014) is an open question.

Ecoevolutionary theory can guide empirical work by elucidating how the evolution of functional traits depends on multiple selection pressures and trait-dependent competitive interactions. In this theoretical study, we model the evolution of breeding phenology in a parid population residing in a heterogeneous landscape, with habitats that differ in their resource phenology. We model selection on breeding phenology as a trade-off between synchrony with resource phenology to maximise parents' reproduction, versus earlier breeding to increase offspring's chance of winning a breeding territory. We explore how breeding phenology responds to landscape composition, the degree of difference between habitat types (strength of carryover effect), and natalhabitat fidelity. 


\section{Materials and methods}

\section{Natural history and model scope}

Four key stages in the life cycle of resident birds were modelled-reproduction, fledgling dispersal and establishment in a winter-flock hierarchy, over-winter survival, and competition for the breeding territory-occurring in a population on a landscape of two (or more) habitat types (Fig. 1). The life-cycle model and assumptions were taken from the singlehabitat model of Johansson et al. (2014), and extended to consider multiple habitat types with different resource phenologies. This choice allowed us to model a concrete scenario that emphasises our mechanisms of interest, namely the trade-off between reproduction and competition, and extend it to a landscape scenario where habitat type influences competitive ability.

Reproduction rate of a predator is generally expected to be maximised when there is a temporal match between its most energy-demanding life-stage and the highest availability of its prey, i.e. the 'match/mismatch hypothesis' (reviewed in Johansson et al. 2015). Birds are also expected to match breeding phenology to resource phenology to match the timing of peak energy-demand, typically of nestlings (Lack 1950, 1954), but alternatively of fledglings (e.g Pakanen et al. 2016) or egg-producing females (e.g Perrins 1970). Our model assumed that the number of fledglings produced was maximised when there was a match between breeding and resource phenology.

Fledglings disperse from the natal territory to join a winter flock, which in many parids contains the breeding pair and a number of adults and juveniles who live in a social dominance hierarchy centred around a breeding territory (Hogstad 1989; Matthysen 1990). Our model concerns birds in which early hatching results in higher fitness, because prior residency in flock or territory establishment affects dominance (e.g. the marsh tit population described in Wesołowski 1998). Competitive advantages from early establishment in

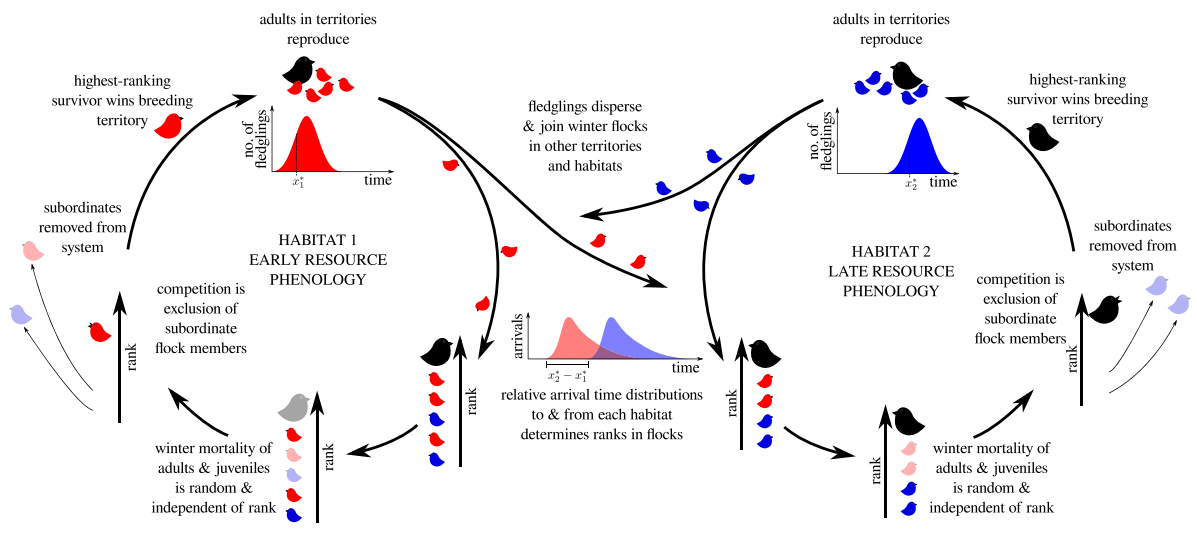

Fig. 1 An illustration of the key stages of the life cycle modelled: reproduction, fledgling dispersal and establishment in a winter-flock dominance hierarchy, over-winter survival, and competition for the breeding territory. Multiple territories exist (not shown) in two habitat types that differ by their resource phenology. Key model assumptions are: number of fledglings produced depends upon synchrony in timing between breeding $\left(x_{i}^{*}\right)$ and resource peak; earlier breeding leads to earlier juvenile dispersal and higher rank in the winter flock (i.e. carryover effect); winter-flock dominance hierarchy is linear and stable; over-winter survival is independent of rank and age; and the winner of the breeding territory is the highest-ranking surviving flock member 
flocks or territories has been demonstrated in multiple bird taxa (Brawn and Samson 1983; Ekman 1989; Cristol et al. 1990; Snell-Rood and Cristol 2005), suggesting that early hatching should give a competitive advantage in social interactions (Eden 1987; Nilsson and Smith 1988; Velando 2000). The prior residence effect may occur because prior residency is an otherwise irrelevant cue for settlement of ambiguous games with a mixed strategy ESS (Maynard Smith 1979; Yasukawa and Bick 1983), or because prior residence confers a direct advantage through site familiarity and accumulated knowledge of the area (Krebs 1982) or the accumulated experience of agonistic encounters (Arcese and Smith 1985; Koivula et al. 1993). Importantly, prior residence can be a strong effect, and has been demonstrated to override other factors of resource-holding potential, such as size and age (Nilsson and Smith 1988; Cristol et al. 1990; Sandell and Smith 1991; Koivula et al. 1993).

When an individual in the flock dies, the model assumed that their position in the hierarchy was filled by the flock-member immediately below in rank, and so on down the hierarchy. This describes species for whom the dominance hierarchy is linear and stable (Hogstad 1989; Hay 2003), and is not universal for parids (reviewed in Ekman 1989).

Given that the prior residence effect was assumed to operate through social rank directly, over-winter survival was given a simple treatment in our model: it was assumed that survival probabilities of all fledglings and adults are equal. In reality, individuals with higher status benefit from priority access to food (Baker 1978; Carrascal et al. 1998; Hay 2003) and lower predation risk foraging areas (Ekman and Askenmo 1984; Hogstad 1988), but may also suffer from higher metabolic rate and reduced immunocompetence (reviewed in Hay et al. 2004).

Competition for the breeding territory was also modelled in a very simple way: ownership goes to the highest-ranking surviving flock member. It was further assumed that all subordinate members are chased away from the territories before the breeding season and die (e.g. marsh tits Nilsson and Smith 1988), so juveniles only have one chance to be recruited to the breeding population.

The single habitat-type model above was extended to multiple habitat types in the following way. We assumed that the effect of hatching date on competitive ability operates regardless of which habitat type the juvenile disperses to, so that natal habitat type has an irreversible carryover effect upon competition sensu O'Connor et al. (2014). It was assumed that each individual has one hatching-date trait per habitat type, which was cued by breeding in that habitat type, so this represented perfect cue response and phenotypic plasticity. This removed all other constraints on breeders' ability to 'match' their breeding to resource phenology, which allowed us to focus upon the effects of competition and carryover effects alone. Finally, while it was assumed that winter-territory selection is random, the model includes a parameter that biases juveniles to join flocks in territories with the same habitat type as their natal territory. This may reflect either coarseness in the spatial distribution of habitat types, or behavioural effects such as natal habitat preference induction (Davis and Stamps 2004).

\section{Ecoevolutionary model}

The ecoevolutionary dynamics of breeding phenology was modelled using the adaptive dynamics framework (Geritz et al. 1999; Brännström et al. 2013). We considered individuals who have a hatching-date $x_{i}$ for each habitat-type $i$, and so their breeding phenology was described as a vector $\mathbf{x}$ of length $h$. We focused mainly on $h=2$ habitat types, i.e. with early and late resource phenology, but the model can be extended to more habitats (see Appendix 
S1). Given that the single-habitat model predicts asynchrony between breeding and resource phenology (Johansson et al. 2014), we focus on hatching-date asynchrony, which we define as the difference between the evolved hatching date $x_{i}^{*}$ and the date that that would maximise the number of fledglings $\hat{x}_{i}$ :

$$
\text { hatching date asynchrony }=x_{i}^{*}-\hat{x}_{i}
$$

We assumed a monomorphic population, so all individuals have the same hatching-date strategy $\mathbf{x}$, and we assumed clonal reproduction (a typical adaptive dynamics assumption).

The adaptive dynamics framework assumes that the population dynamics are fast relative to evolutionary dynamics (i.e. separation of timescales), so the ecological dynamics can be assumed to be at steady-state when a mutant hatching-date strategy $\mathbf{y}$ appears. Therefore the model involved a two-step process detailed below: (1) the ecological dynamics for a monomorphic population, with population size as a function of breeding phenology, were resolved to their steady state; then (2) given the solution found for the ecological steady state, the steady-state of the evolutionary dynamics were found.

\section{Ecological dynamics}

\section{Reproduction}

The number of fledglings produced by each individual in habitat $i$ is modelled as a Gaussian function of the difference between its hatching-date trait $x_{i}$ and the resource-synchronous hatching date $\hat{x}_{i}$ in that habitat

$$
E_{i}\left(x_{i}\right)=E_{0, i} \exp \left(-\frac{\left(x_{i}-\hat{x}_{i}\right)^{2}}{2 \sigma_{E, i}^{2}}\right),
$$

where $E_{i}\left(x_{i}\right)$ is the number of fledglings produced, $E_{0, i}$ is the maximum number of fledglings that can be produced in habitat $i$, and $\sigma_{E, i}$ is a parameter describing the width of the temporal distribution resource in habitat $i$. Therefore individuals maximise their reproduction by synchronising their hatching date in each habitat type to the resource-synchronous hatching date in that habitat type.

\section{Dispersal and habitat-type fidelity}

Winter territory selection is modelled as random, without regard to the number of other juveniles in the flock, however a parameter is included to account for natal habitat-type fidelity. It is assumed that a fraction $r$ of juveniles will choose a territory at random, so that the habitat type is selected in proportion to its frequency in the landscape, while the remaining $1-r$ will only select from territories with the same habitat type as their natal territory. Then the proportion $p_{i, j}$ of juveniles dispersing from habitat-type $i$ to habitat-type $j$ is (c.f. Ives and Andow 2002)

$$
p_{i, j}= \begin{cases}\frac{K_{j}}{\sum_{l=1}^{h} K_{l}} r, & \text { if } \quad i \neq j \\ (1-m)+\frac{K_{j}}{\sum_{l=1}^{h} K_{l}} r, & \text { if } \quad i=j\end{cases}
$$


where $h$ is the number of different habitat types, and $K_{i}$ the number of territories with habitat-type $i$ in the landscape.

\section{Prior residence effect and recruitment}

In order to describe the relationship between hatching date and a juvenile's probability of obtaining first rank in the winter-flock dominance hierarchy, three intermediate steps are modelled: (1) the translation of hatching date in a particular habitat type to a probability distribution of arrival times to the winter flock (Eq. 4); (2) the arrival rates of juveniles from all habitat types to a given territory (Eq. 5); and (3) the probability that a given juvenile will, at the end of winter, rank first in the dominance hierarchy given 1 and 2 (Eq. 7). A juvenile is recruited into the adult breeding population if it has first rank in the dominance hierarchy and the territory has no adult owner at the end of winter (Eq. 9).

Rank is determined by an individual's time of arrival to the winter flock relative to its competitors. If we assume that the time from hatching to family break-up is a constant, then arrival time is only influenced by differences in hatching date between habitats. Therefore we describe the probability distribution of relative arrival times $t$ of a juvenile to any winter flock as lognormal relative to their hatching date $x_{i}$

$$
g\left(t, x_{i} ; \mu_{g}, \sigma_{g}\right)=\frac{1}{\left(t-x_{i}\right) \sigma_{g} \sqrt{2 \pi}} \exp \left(-\frac{\left(\ln \left(t-x_{i}\right)-\mu_{g}\right)^{2}}{2 \sigma_{g}^{2}}\right),
$$

where $\mu_{g}$ and $\sigma_{g}$ are the scale and shape parameters, respectively. For a fixed $\sigma_{g}$, the arrival distribution may also be described by the mean arrival time $m_{g}=e^{\mu_{g}+\sigma_{g}^{2} / 2}$. Mean arrival time $m_{g}$ can also be interpreted as the mean number of days after family group break-up that juveniles arrive at winter flocks, and is used to parameterise the models below.

Because we now have a description of the probability distribution of arrival times of a fledgling from each habitat type, it can be combined with the number of fledglings produced in each habitat type to give the arrival rates of juveniles from all habitat types to a territory with habitat type $j$ who will survive the coming winter (proportion $s_{j}$ )

$$
\lambda_{j}(t, \mathbf{x}, \mathbf{n})=\frac{s_{j}}{K_{j}} \sum_{i=1}^{h} n_{i} E_{i}\left(x_{i}\right) g\left(t, x_{i}\right) p_{i, j}
$$

where $\mathbf{x}$ is the vector of hatching dates $x_{i}$ and $\mathbf{n}$ is the vector of population sizes $n_{i}$ in each habitat type, and the sum is taken over each of the habitat types including $j$ itself. Equation 5 can be understood as follows: for a given habitat-type $i$ from which juveniles are dispersing, $n_{i} E\left(x_{i}\right)$ is the number of fledglings produced in that habitat type, $g\left(t, x_{i}\right)$ is their arrival distribution given that they hatched at date $x_{i}$, and $p_{i, j}$ is the probability of them travelling to habitat-type $j$, so the rate of arrival to habitat-type $j$ is the sum over all $i$ divided by the number territories of type $j$.

To obtain the probability of being first in the dominance hierarchy, it is assumed that arrival is a Poisson process, so the probability that a juvenile with a particular relative arrival time $\tau$ takes the first position in a flock in habitat $j$ is

$$
f_{j}(\tau, \mathbf{x}, \mathbf{n})=\exp \left(-\int_{\min (\mathbf{x})}^{\tau} \lambda_{j}(t, \mathbf{x}, \mathbf{n}) d t\right) .
$$


Juveniles from habitat $i$ have relative arrival times distributed according to Eq. 4 with $x_{i} \leq t<\infty$. Therefore the probability of any juvenile from habitat $i$ obtaining the first position when joining a flock in habitat-type $j$ is the integral of $f_{j}$ over their arrival time distribution

$$
F_{i, j}(\mathbf{x}, \mathbf{n})=\int_{x_{i}}^{\infty} g\left(t, x_{i} ; \mu_{g}, \sigma_{g}\right) f_{j}(t, \mathbf{x}, \mathbf{n}) d t .
$$

A territory will have no adult owner at the end of winter either because it was unoccupied in previous breeding season, or because it did have an owner but they died. Therefore the probability that a territory in habitat $j$ has no adult owner at the end of the winter is

$$
A_{j}\left(n_{j}\right)=\frac{K_{j}-s_{j} n_{j}}{K_{j}} .
$$

In order for a juvenile to be recruited into the adult population, it must: (1) come first of the surviving juveniles in the territory, $F_{i, j}$; (2) survive the winter itself, $s_{j}$; and (3) choose a territory that will have no adult owner at the end of the winter, $A_{j}$. Therefore the per-capita recruitment rate from habitat-type $i$ to habitat-type $j$ is

$$
w_{i, j}(\mathbf{x}, \mathbf{n})=p_{i, j} E_{i}\left(x_{i}\right) s_{j} F_{i, j}(\mathbf{x}, \mathbf{n}) A_{j}\left(n_{j}\right) .
$$

\section{Steady-state population size and recruit flow between habitats}

The number of adults in habitat-type $i$ at year $t+1$ is modelled as a system of difference equations

$$
n_{i, t+1}(\mathbf{x})=s_{i} n_{i, t}(\mathbf{x})+\sum_{j=1}^{h} w_{j, i}\left(\mathbf{x}, \mathbf{n}_{t}\right) n_{j, t}(\mathbf{x}) .
$$

It is convenient for understanding to express this in matrix form. For two habitat types for example, the system of equations obtained from Eq. 10 is written

$$
\left(\begin{array}{l}
n_{1} \\
n_{2}
\end{array}\right)_{t+1}=\left(\begin{array}{cc}
s_{1}+w_{1,1}\left(\mathbf{x}, \mathbf{n}_{t}\right) & w_{2,1}\left(\mathbf{x}, \mathbf{n}_{t}\right) \\
w_{1,2}\left(\mathbf{x}, \mathbf{n}_{t}\right) & s_{2}+w_{2,2}\left(\mathbf{x}, \mathbf{n}_{t}\right)
\end{array}\right)\left(\begin{array}{l}
n_{1} \\
n_{2}
\end{array}\right)_{t}
$$

Define a matrix $W\left(\mathbf{x}, \mathbf{n}_{t}\right)$ with elements $w_{i, j}\left(\mathbf{x}, \mathbf{n}_{t}\right)$, and a matrix $\operatorname{diag}(\mathbf{s})$ with elements $s_{i}$ along the diagonal, then the matrices can be combined to define the $2 \times 2$ matrix that appears on the right-hand side of Eq. 11

$$
U\left(\mathbf{x}, \mathbf{n}_{t}\right)=\left(W\left(\mathbf{x}, \mathbf{n}_{t}\right)+\operatorname{diag}(\mathbf{s})\right)^{T}
$$

Therefore the system of difference equations in Eq. 10 can also be written

$$
\mathbf{n}_{t+1}(\mathbf{x})=U\left(\mathbf{x}, \mathbf{n}_{t}\right) \mathbf{n}_{t}(\mathbf{x})
$$

which can be solved numerically to find the steady-state population size $\mathbf{n}_{t+1}(\mathbf{x})=\mathbf{n}_{t}(\mathbf{x})=\mathbf{n}^{*}(\mathbf{x})$, and the stability of the steady-state can be verified numerically (Appendix S3).

Equation 13 says that the population growth or decline rate results from the product of the sequence of matrices $U\left(\mathbf{x}, \mathbf{n}_{t}\right)$. At the ecological steady state, the population size neither increases nor decreases, therefore its growth rate is 1 . This growth rate is the result of the 
repeated products of $U\left(\mathbf{x}, \mathbf{n}^{*}\right)$, therefore the growth rate can also be calculated as the dominant eigenvalue of the matrix

$$
\max \left(\operatorname{Re}\left(\operatorname{eig}\left(U\left(\mathbf{x}, \mathbf{n}^{*}\right)\right)\right)\right)=1 .
$$

Recruit flow between habitats at the population steady-state is quantified by finding the proportion of recruits to habitat $j$ that were from habitat $i$

$$
\phi_{i, j}(\mathbf{x})=\frac{w_{i, j}\left(\mathbf{x}, \mathbf{n}^{*}\right) n_{i}^{*}}{\sum_{k=1}^{h} w_{k, j}\left(\mathbf{x}, \mathbf{n}^{*}\right) n_{k}^{*}} .
$$

We call recruitment insular when most new recruits to all habitats originated in that same habitat, i.e. if all $\phi_{i, i} \geq 0.5$. This can be contrasted with asymmetric recruitment, where one habitat (typically the late habitat) receives more new recruits from the other habitat (typically the early habitat), i.e. if at least one of the $\phi_{i, i}<0.5$.

\section{Ecoevolutionary dynamics}

To analyse the ecoevolutionary dynamics we consider the scenario of a rare mutant hatching-date strategy $\mathbf{y}$ invading a steady-state population where the prevailing hatching-date strategy is $\mathbf{x}$ (Appendix A, Kisdi 2002). Because it is assumed that the mutant is rare and that the $\mathbf{x}$-strategist population is at steady state, then we know that the $\mathbf{x}$-strategists have a growth rate of 1 (Eq. 14). Therefore in order for the rare mutant strategy to invade, it will need a growth rate during invasion that is greater than 1 .

The growth rate of the rare mutant strategy is obtained as follows. The probability of a mutant obtaining the first position when travelling from habitat-type $i$ to habitat-type $j$ is

$$
F_{i, j}\left(y_{i}, \mathbf{x}, \mathbf{n}^{*}\right)=\int_{y_{i}}^{\infty} g\left(t, y_{i} ; \mu_{g}, \sigma_{g}\right) f_{j}\left(t, \mathbf{x}, \mathbf{n}^{*}\right) d t
$$

and its per-capita recruitment rate between habitats is

$$
w_{i, j}\left(y_{i}, \mathbf{x}, \mathbf{n}^{*}\right)=p_{i, j} s_{j} E_{i}\left(y_{i}\right) F_{i, j}\left(y_{i}, \mathbf{x}, \mathbf{n}^{*}\right) A_{j}\left(n_{j}^{*}\right)
$$

where $\mathbf{n}^{*}$ again refers to the steady-state population sizes of the prevailing $\mathbf{x}$-strategists. Similar to Eq. 12, the growth rate of the rare mutant with strategy $\mathbf{y}$ is determined by the repeated product of the matrix

$$
U\left(\mathbf{y}, \mathbf{x}, \mathbf{n}^{*}\right)=\left(W\left(\mathbf{y}, \mathbf{x}, \mathbf{n}^{*}\right)+\operatorname{diag}(\mathbf{s})\right)^{T} .
$$

Then the growth rate of the rare mutant strategy, which is also called the invasion fitness, is the real part of the dominant eigenvalue of $U\left(\mathbf{y}, \mathbf{x}, \mathbf{n}^{*}\right)$

$$
\Lambda(\mathbf{y}, \mathbf{x})=\max \left(\operatorname{Re}\left(\operatorname{eig}\left(U\left(\mathbf{y}, \mathbf{x}, \mathbf{n}^{*}\right)\right)\right)\right) .
$$

$\Lambda(\mathbf{y}, \mathbf{x})$ is called the invasion fitness because it indicates whether or not the invading mutant's population size will increase or decrease. For example, if the mutant strategy was the same as the resident strategy $\mathbf{y}=\mathbf{x}$, then $U\left(\mathbf{y}, \mathbf{x}, \mathbf{n}^{*}\right)=U\left(\mathbf{x}, \mathbf{n}^{*}\right)$ and $\Lambda(\mathbf{y}, \mathbf{x})=1$. If $\Lambda(\mathbf{y}, \mathbf{x})>1$ then the mutant's population size will increase and it can invade the population, whereas and if $\Lambda(\mathbf{y}, \mathbf{x})<1$ then it will decrease until it is removed.

The evolutionarily singular strategy $\mathbf{x}^{*}$ is found when the fitness gradients are zero

$$
g_{i}(\mathbf{x})=\left.\frac{\partial \Lambda(\mathbf{y}, \mathbf{x})}{\partial y_{i}}\right|_{\mathbf{y}=\mathbf{x}}=0
$$


so the evolutionarily singular strategy $\mathbf{x}^{*}$ satisfies $\mathbf{g}\left(\mathbf{x}^{*}\right)=0$. If the evolutionarily singular strategy is at a peak in the fitness landscape, then it is evolutionarily stable, which means that a population with that strategy cannot be invaded by a rare mutant strategy. The evolutionary stability of the singular strategy can be established by investigating the Hessian and Jacobian matrices (Leimar 2009) (see Appendix S4). If an evolutionarily singular strategy is both a fitness maximum and an evolutionary attractor then it is known as the continuously stable strategy (CSS) (Geritz et al. 1999), which represents the expected endpoint of gradual, evolutionary change, barring genetic correlations and other constraints (Dieckmann and Law 1996; Teplitsky et al. 2014) or trade-offs with other fitness components not considered in the model.

The selection of the default parameter values can be found in Table 1, and details found in Appendix S2.

\section{Results}

\section{Hatching date evolves to occur earlier than resource synchrony}

In both the early and late habitats, the hatching dates evolve to a single continuously stable strategy (Fig. S3, Fig. S5) and this hatching-date strategy is always earlier than the resource-synchronous hatching date that would maximise the number of fledglings produced (Fig. 2a). Therefore we present the remainder of results in terms of the magnitude of asynchrony between bird and resource phenology (c.f. Fig. 2a, b), which is calculated according to Eq. 1 .

\section{Degree of asynchrony depends on difference in resource phenology between habitats}

In both habitats, the magnitude of asynchrony is smallest when the difference in resource phenology between habitats, and therefore the strength of the carryover effect, is greatest. This is true for the default parameter values (Fig. 2b) and across the parameter space (examples in Fig. 2, all parameters in Fig. S2).

The relationship between asynchrony and difference in resource phenology differs qualitatively between habitat types. In the early habitat, the relationship is monotonic, so that asynchrony always increases as the difference in resource phenology between habitats decreases to zero (red curves in Fig. 2). In the late habitat however, the relationship is hump-shaped, so that the magnitude of asynchrony is largest when the difference in resource phenology between habitats is some small value (blue curves in Fig. 2).

As a consequence of the qualitative differences above, testable predictions of the relationship between breeding phenology and habitat types depend upon the parameter values and the strength of the carryover effect (Fig. 3). For example, if one were comparing the breeding phenologies of two species who differed in mean arrival time, then the early-arriving species will be more asynchronous than the late species. However each species may be more or less asynchronous in the early compared to late habitat, depending upon how different the resource phenologies are and the mean arrival times themselves (Fig. 3a-c). The existence of different patterns depends upon the other parameters. For example, the asynchrony curves in each habitat may cross each other 0,1 , or 2 times, depending upon the width of the resource peak in the late habitat (compare Fig. 2d, f; full 


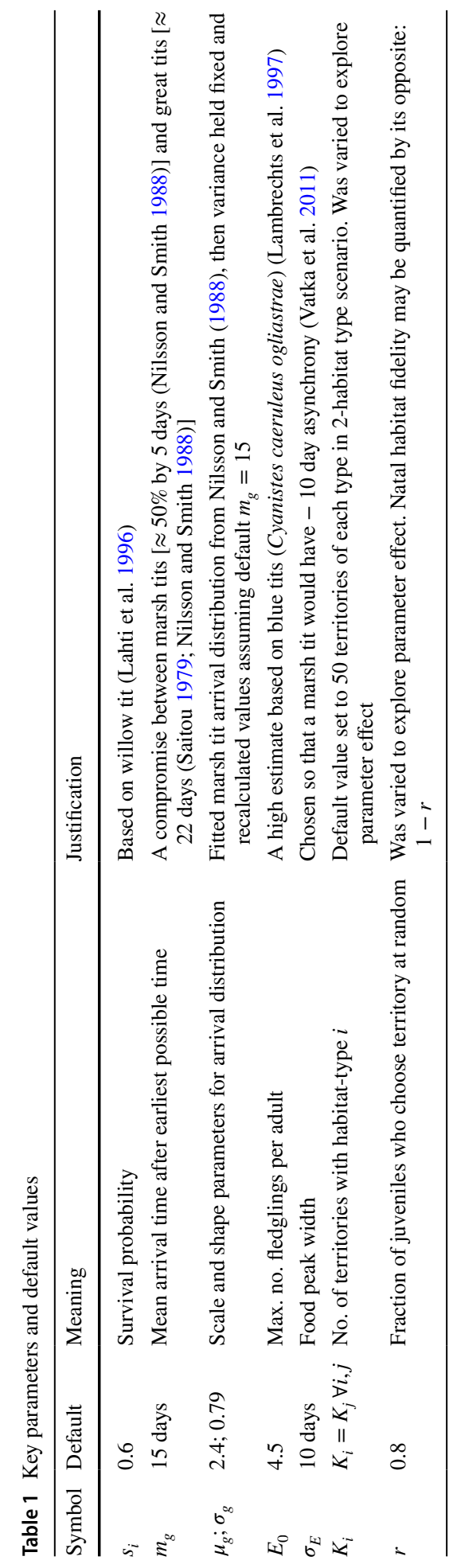



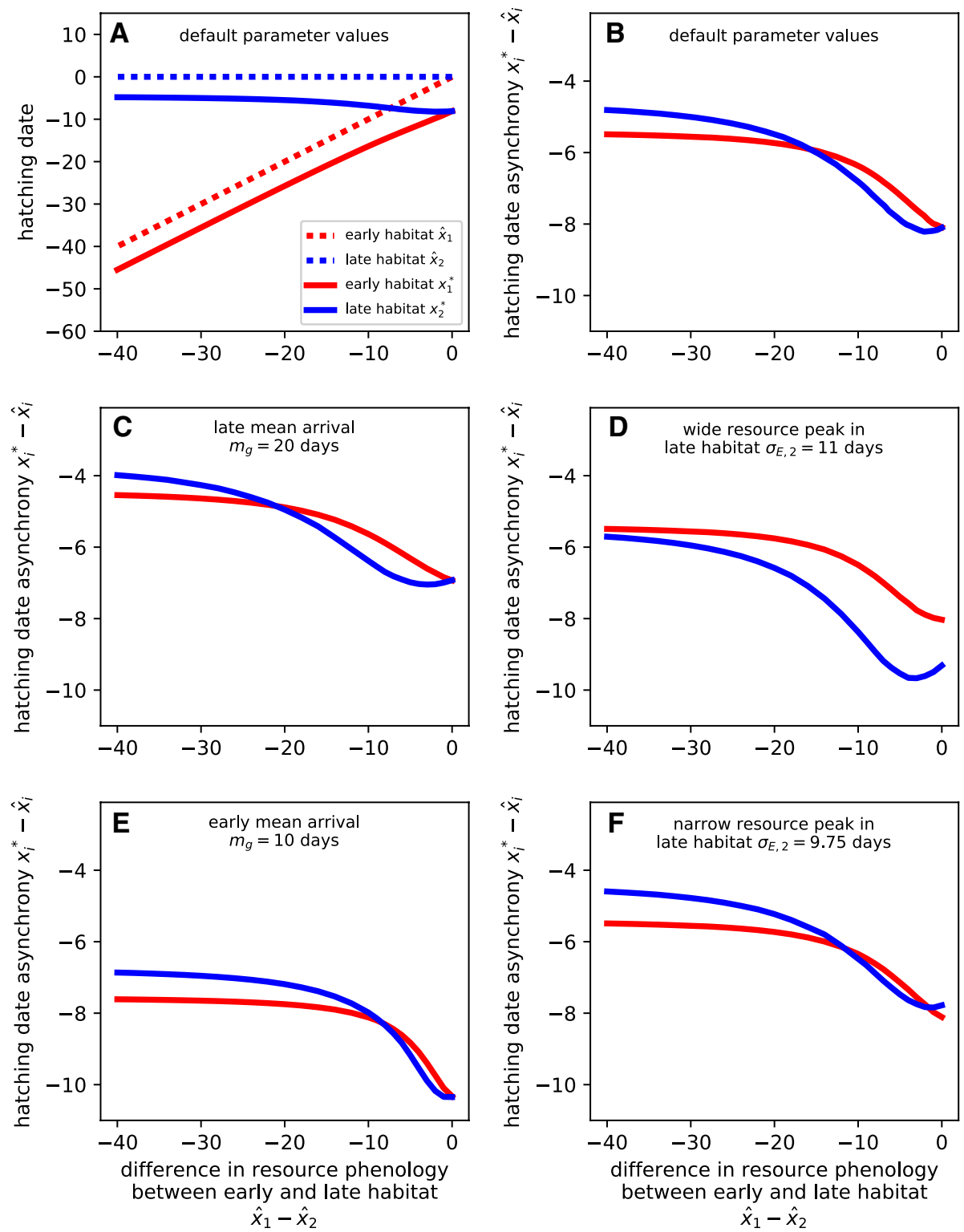

Fig. 2 The effect of the difference in resource phenology between habitat types upon the relative hatching date (a), and upon the hatching date asynchrony (b-f), at the continuously stable strategy (i.e. evolutionary end-point). The carryover effect is absent when the difference in resource phenology between habitats is zero. In the early habitat (red lines), the magnitude of asynchrony decreases monotonically with increasing difference in resource phenology, whereas in the late habitat (blue lines) asynchrony is largest at some small value of resource phenology difference. The results shown are for the default parameter values $(\mathbf{a}, \mathbf{b})$, for high and low values of the mean arrival time after earliest possible arrival $m_{g}(\mathbf{c}, \mathbf{e})$, and for high and low values of the width of the resource peak in the late habitat $\sigma_{E, 2}(\mathbf{d}, \mathbf{f})$. (Color figure online) 

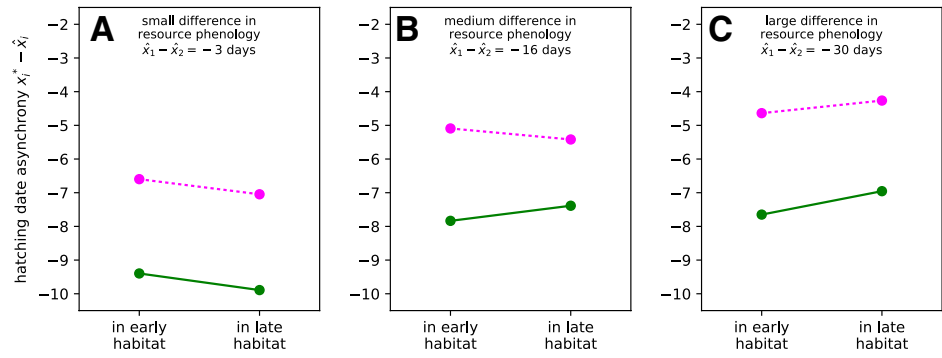

mean arrival time of species early ( $m_{g}=10$ days)


which habitat type more common:

$\longrightarrow$ L late $(70: 30)$ $\ldots . . .$. early $(70: 30)$

Fig. 3 Model predictions for hypothetical cross-species $(\mathbf{a}-\mathbf{c})$ and cross-landscapes (d-f) comparisons of breeding phenologies. Breeding phenology may be more or less asynchronous in the early compared to late habitat, depending upon the difference in resource phenology between habitat types

results in Fig. S2) and these cross-overs separate regions where asynchrony is greater in the early or late habitat.

\section{Recruitment is typically asymmetric, from early to late habitat, but may be reversed early-habitat disadvantages}

The carryover effect promotes asymmetric recruitment, with most recruits to both the early and late habitats coming from the early habitat (Fig. 4; see Fig. S4 for all parameter values). However this asymmetry can be reversed if the early habitat is disadvantageous in certain ways, for example if the early habitat is less frequent in the landscape, or produces fewer offspring per territory. A disadvantage in the early habitat shifts the balance of recruitment to more recruits coming from the late habitat (to the left of the vertical dotted lines in Fig. 4b, c, e, f, respectively). Natal habitat-type fidelity creates a region in the parameter space where most new recruits to each habitat type will have originated from that same habitat type, i.e. insular recruitment (Fig. 4a, d; Fig. S7). Therefore if the carryover effect is combined with natal habitat-type fidelity, a disadvantage in the early habitat can lead to insular recruitment (Fig. 4c, f).

\section{Discussion}

Our model assumed that breeding phenology involved a trade-off between reproduction and competition, and further assumed that natal habitat type had a carryover effect upon competitive ability. We have explored how this scenario will determine the evolution of breeding phenology and the rates of recruitment between habitat types. 

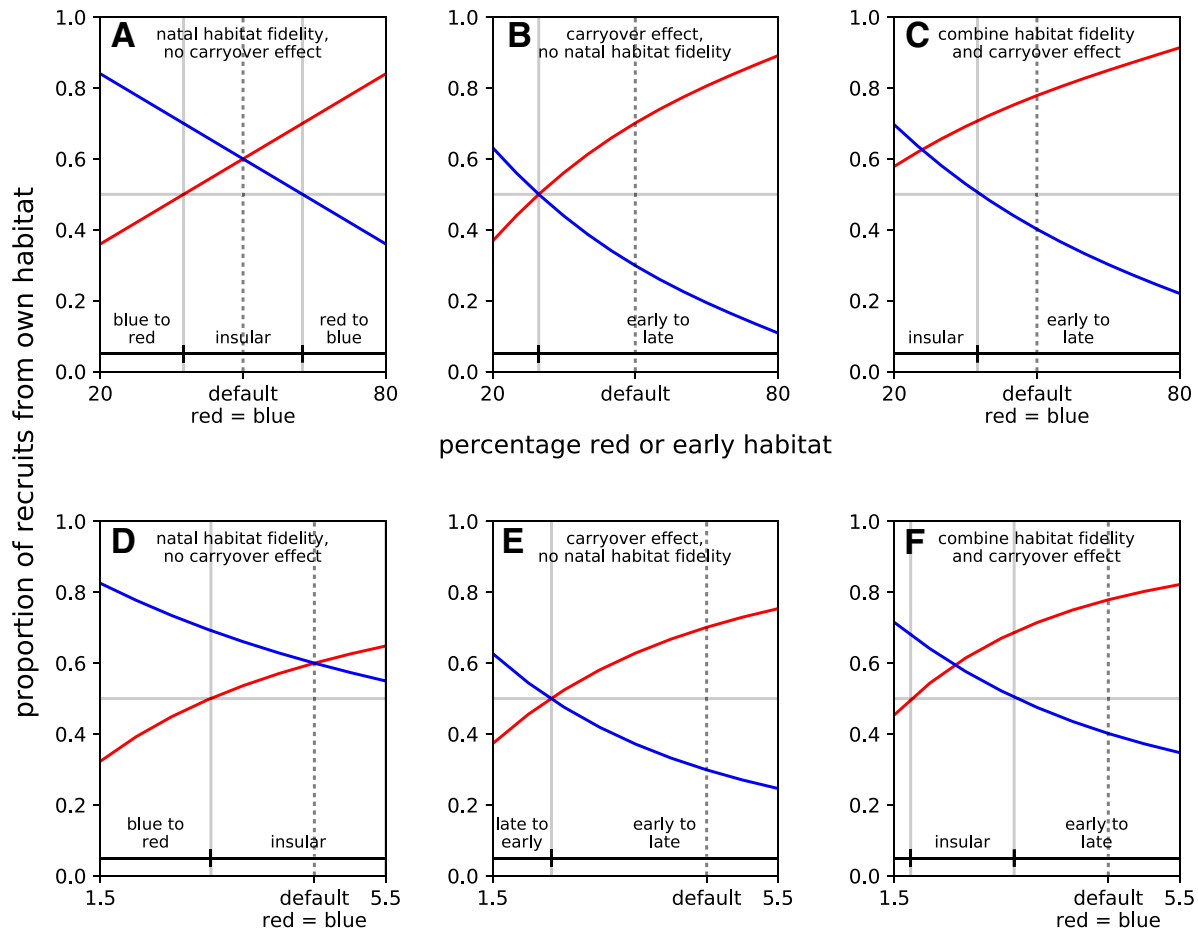

percentage red or early habitat
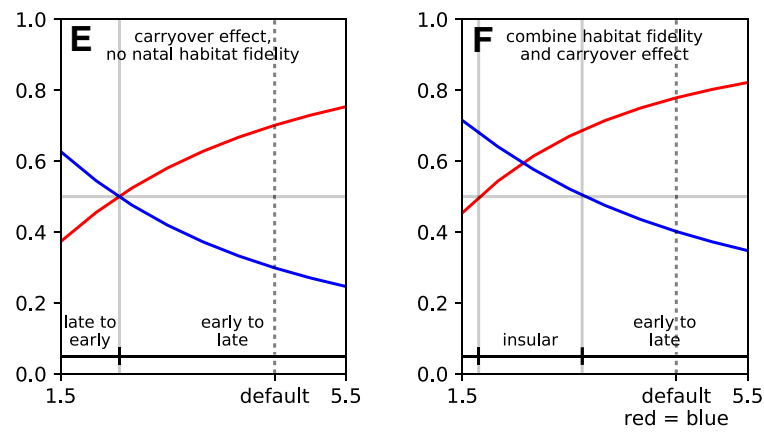

Fig. 4 The proportion of recruits to each habitat type that originated from that same habitat $\left(\phi_{i, i}\right)$, for combinations of presence/absence of natal habitat-type fidelity $(1-r=0.2)$ and presence/absence of carryover effect $\left(\hat{x}_{1}-\hat{x}_{2}=15\right.$ days). The default parameter values, where both habitats are otherwise equal, is shown by a dotted line. The effect of natal habitat-type fidelity $(\mathbf{a}, \mathbf{d})$ is to create a region in parameter space where recruitment is insular (i.e. proportion in both habitat types $\left.\phi_{i, i}>0.5\right)$. The effect of the carryover effect $(\mathbf{b}$, e) is to cause asymmetric recruitment from the early to late habitat. When natal habitat-type fidelity and carryover effect are combined as in the default model $(\mathbf{c}, \mathbf{f})$, recruitment is asymmetric, however the asymmetry can be reversed or become insular if a lower percentage of the landscape is early habitat or early habitat has lower productivity

\section{Model predictions}

Similar to the single-habitat model from which our model is derived (Johansson et al. 2014), our model predicts that hatching date will be asynchronous and earlier than resource phenology. This prediction follows as a logical consequence of the assumption that breeding phenology involves a trade-off between reproduction and competition. This trade-off relationship is also key to interpreting the basic results of our model. For example, a wider resource peak (high $\sigma_{E, 2}$ ) lowers the reproductive cost of asynchrony, and an earlier mean arrival time (low $m_{g}$ ) strengthens competition, therefore both increase the magnitude of asynchrony (Fig. 2d, e).

The model assumes that offspring who hatch earlier are competitively advantaged, and this carryover effect on competition is key to understanding the model's other predictions about recruit flow and asynchrony. Juveniles raised in the early habitat typically hatch and fledge earlier than juveniles raised in the late habitat (Fig. 2a), which gives them the advantage in breeding territory competition. This difference in competitive 
ability is a carryover effect sensu O'Connor et al. (2014): the effect is initiated at an early life stage (i.e. at hatching) but its fitness consequences manifest at a later life stage (i.e. breeding territory competition), and the effect is carried with each juvenile regardless of which habitat it disperses to. This carryover effect influences recruit flow because, all else being equal, juveniles from the early habitat have a higher probability of being recruited into the adult population in both habitat types. This carryover effect also influences the selective trade-off between competition and reproduction in each habitat. For example, when there are many weak-competitor juveniles from the late habitat in the population, then the competition component of selection on hatching date in the early habitat is less important.

Whether the hatching date in the late habitat evolves to become more synchronous or less synchronous than in the early habitat (Fig. 3) depends upon whether compensating for the late habitat's competitive disadvantage is worth the reproductive cost. The larger the difference is between the resource phenologies in each habitat, the stronger the carryover effects are, and the larger the competitive disadvantage is of being raised in the late habitat. Then juveniles from the early habitat are faced with fewer strong competitors, which decreases the importance of the competition component of the selective tradeoff, shifting the selective balance towards greater reproduction and increased synchrony. Meanwhile, juveniles in the late habitat must somehow compensate for their competitive disadvantage. One way is to improve competitive ability by evolving to have an even earlier and more asynchronous breeding phenology. However asynchrony comes at a reproductive cost, which is only worthwhile when the difference in resource phenology between habitats is small. When the difference in resource phenology between habitats is large, then it is not possible for juveniles in the late habitat to hatch early enough to compete with those from the early habitat without also greatly reducing the number of fledglings their parents produce. In that case, the only possible way to compensate is to increase synchrony with the resource phenology, to produce a larger number of fledglings albeit with low competitive ability each.

When the carryover effects are strong enough (i.e. large difference in resource phenology between habitats), recruit flow between habitats is typically asymmetric, therefore a source-sink like relationship is created between habitats by a carryover effect. Hatching date in the late habitat can only evolve to compensate for its competitive disadvantage when the difference in resource phenology between habitats is small enough that it is worth the reproductive cost. When compensation does not occur, juveniles from the early habitat are competitively advantaged, and therefore most recruits to both the early and late habitat were raised in the early habitat (Fig. 4 and Fig. S1). This asymmetric recruitment creates a source-sink like relationship between habitats; however, in contrast to traditional sourcesink dynamics, which are caused by a difference in habitat quality such that the sink cannot sustain a population in the absence of the source (e.g. Pulliam 1988), in our model the population in the late habitat can be sustained in isolation.

The asymmetric recruitment from early to late habitat can be reversed if the early habitat is less frequent in the landscape or produces fewer offspring. In cases where that is combined with natal-habitat fidelity, then the asymmetric recruit flow between habitats (above) can be replaced with a more insular pattern (Fig. 4). Natal-habitat fidelity may occur due to behavioural effects, such as natal-habitat preference induction (Grunberger and Leisler 1990; Davis and Stamps 2004) or a condition-dependent habitat choice (cf. Verhulst et al. 1997). Natal-habitat fidelity may also occur due to a coarse-grained landscape such that territories of similar habitat type are more likely to occur in closer spatial proximity to one another. 


\section{Empirical relevance}

Our hypothesised mechanism, of a competition-reproduction trade-off, could explain why some populations of willow tits (Vatka et al. 2011), coal tits (Both et al. 2009) and marsh tits (Wesołowski 1998) have historically bred before the peak in nestling food resources. Asynchronous breeding phenology is not universal (e.g. Both et al. 2009), however in cases where it does occur, a trade-off with competition is often discussed as a likely cause (e.g Wesołowski 1998; Vatka et al. 2011; Pakanen et al. 2016; Källander et al. 2017). For example, when discussing how marsh tits breed much earlier than other species in the area, Wesołowski (1998) emphasised the strong negative correlation in this species between relative fledging time and the juvenile's probability of successfully establishing.

We also propose that our broader hypothesis, that breeding phenology is influenced by competition at other life stages, is supported by its apparent ability to explain synchrony/asynchrony differences between migratory and non-migratory birds. For example, Both et al. (2009) contrasts a population of pied flycatchers (Ficedula hypoleuca), whose maximal nestling food-demand occurs after the resource peak, and therefore whose synchrony has decreased with climate-induced food-peak advance, to a population of coal tits whose maximal demand occurs before the peak and whose synchrony has increased. The pied flycatcher is a migratory species and competition for territories is also subject to the prior residence effect (Alatalo et al. 1986; Kokko 1999); however if the food peak is early enough then breeding synchrony with the food peak is traded against adult survival during migration and in the early season, resulting in a breeding date that is later than the peak (Johansson and Jonzén 2012; Kristensen et al. 2015). In contrast, the coal tit is a winter-resident species, for which no such trade-off with migration and survival exists. Instead, we propose that the prior residence effect gives the juveniles of early-breeding parents a competitive advantage in territory competition via earlier natal dispersal. Therefore synchrony is traded against juvenile competitive ability resulting in a breeding date that is earlier than the peak (Johansson et al. 2014).

Empirical evidence for the heterogeneous landscape effects that we predict has not been reported in the resident-bird literature, and so our model serves only to predict what we expect to occur in the scenario envisaged. We believe that marsh tits, willow tits, and coal tits are good candidates for testing our model. We also note that phenological heterogeneity of the type we envisage is common, such as landscapes with a mix of deciduous (early phenology) and evergreen (late phenology) habitat (e.g. Dias et al. 1996; Vatka et al. 2011).

Other taxonomic groups also face situations where where the natal habitat type influences competitive ability and there is a pressure to trade-off with other traits relevant to fitness. For example (Kavanagh et al. 2010), young grayling fish (Thymallus thymallus) developing in cold tributaries hatch late and so have restricted time to reach sufficient size to survive the first winter. The pressure to grow faster and in a colder environment induces a trade-off between muscle and skeletal development. In addition, after developing in separate tributaries for the first few months of their lives, juveniles from cold tributaries move to lakes where they must compete for food resources with larger and more competitive juveniles from warmer tributaries. Therefore we expect that graylings from cold tributaries, similar to our model birds from late habitat, are under a double burden of trade-off pressure: first to obtain sufficient size to meet survival requirements and to compete with each other, and second to compete with individuals from other natal habitats who are competitively advantaged due to carryover effects. 
Our model predicts when carryover effects will lead to source-sink dynamics or insularity, and these different recruitment patterns may have implications for gene flow and local adaptation (Kristensen et al. 2018). Habitats that differ in phenology also differ in other characteristics, e.g. deciduous forests with early resource phenology have different physical structure and are often richer than evergreen forests with late resource phenology (Braillet et al. 2002). Therefore populations may have other characteristics that are under different selection pressures in the different habitat types, such as clutch size, body size, and other morphometric and behavioural traits (Blondel 2007; Charmantier et al. 2016). Sourcesink dynamics often lead to maladapation to the sink habitat, due to gene-swamping and because the sink contributes less to the future gene pool (Holt 1996). Therefore we may expect that asymmetric recruitment, with higher gene-flow from the early to late habitat type, will favour adaptation of birds' other traits to the the early habitat's other characteristics (c.f. Dias and Blondel 1996). In contrast, the insular pattern of recruit flow will reduce gene flow between habitat types. If the population is under divergent selection, then reducing the gene flow between habitats may initiate a positive feedback leading to a pattern of isolation by ecology (Shafer and Wolf 2013).

\section{Model caveats}

Our model makes a number of simplifying assumptions, and is structured to emphasise the mechanisms of interest, therefore the strength of the patterns predicted by the model will depend upon how well a particular species and system matches these assumptions.

The model is premised on the match/mismatch hypothesis (reviewed in Johansson et al. 2015), and so it was assumed that the number of fledglings produced is directly determined by a match between breeding phenology and resource phenology. Synchrony with resource timing is expected to exert a major selection pressure on resident birds (Visser et al. 1998); for example, asynchrony has been suggested as a yardstick to measure how well natural populations have adapted to climate change (Visser and Both 2005). However to speak of 'synchrony' also implies a strongly temporally-peaked resource curve [e.g. peaks in the abundance of caterpillars (Sanz 2001; Veen et al. 2010)] with a strong penalty for missing the peak (for counter-example see Wesołowski and Rowiński 2014). This is commonly reported (e.g. Visser et al. 1998) and assumed in models (e.g. Kristensen et al. 2015), but not necessarily certain nor applicable in all systems (reviewed in Cholewa and Wesołowski 2011), and greatly simplifies the reality of multiple peaks of alternative food resources that vary year-to-year (Vatka et al. 2016).

We focused on discrete-flocking systems such as the marsh tit (Nilsson and Smith 1988) and willow tit (Hogstad 1987), and so the model assumed that the carryover effect influenced rank which in turn directly determined which flock member won the breeding territory. An alternative model would have been that rank improves over-winter survival, e.g. via priority access to food or lower predation-risk foraging areas, which determines recruitment probability indirectly.

The details of the winter social system in parids vary both between (Ekman 1989; Matthysen 1990) and within (Nilsson and Smith 1988; Broughton et al. 2015) species. For our hypothesis, it is irrelevant if the early hatching results in higher likelihood to obtain the breeding territory due to social dominance directly or due to higher survival probability, as long as the mechanism is prior residency, and available evidence suggest social advantages in winter flocks and territory establishment from early hatching (Nilsson and Smith 1988; Nilsson 1990, 1999). 
The model makes a strong assumption about the durability of the carryover effect: when an individual in the flock dies, its position in the rank is filled by the flock-member immediately below in rank, and so on down the hierarchy. This is a reasonable assumption for species with stable dominance hierarchies (Hogstad 1989; Hay 2003), but that is not universal. For example, in black-capped chickadees (Parus atricapillus) recruitment can occur from the bottom of the rank (reviewed in Ekman 1989). Our assumption is also consistent with the 'hopeful dominants' scenario: that in saturated environments juveniles join flocks to await the death of the territory owners and individuals with higher status for their chance to breed (Lahti et al. 1996). Therefore our model also omitted other mechanisms for improving rank such as surveying nearby flocks (e.g. Hogstad 1999). Deviations from these assumptions will weaken the mechanisms in our model, though provided that natal habitat has some effect on competitive ability, then the predicted patterns will remain true.

The model assumes that non-breeders have zero survival. This is the simplest possible way to link prior residence to competition, however there are many species in which winter-flocks include non-breeders from the previous year (reviewed in Ekman 1989). Nevertheless it is not a biologically unreasonable assumption; for example, empirical data on marsh tits (Nilsson and Smith 1988) have indicated that non-breeders to large extent disappear from the system through mortality or have low reproductive success, as a consequence of being expelled to marginal habitats. An alternative would have been a more complicated, age-structured, model, which would also permit us to model difference in survival probability between age groups. We expect that variation in these survival rates would affect our predictions. For example, increasing non-breeder survival and assuming they engage in competition for territories would make it less likely that an early born offspring obtains a territory in its first year, and would reduce selection for early reproduction. However, even if we assume equal survival and equal competitive ability of breeders and non-breeders, we still expect the ESS to deviate somewhat from the reproductive maximum $\left(\hat{x}_{i}\right)$. An early and a late born offspring would namely have the same prospects of reproducing from year two onward and thus prior-residency effects among one-year-olds would still convey some advantage for early reproduction. The scenario studied here, with zero non-breeder survival, is however of particular interest because therein all individuals that contribute to fitness are found in a single state, at a single time point in time and the model can be collapsed to non-structured model. That greatly facilitates the analytical study of its evolution, as shown here, and in this way our study serves as a reference point for investigations of more complex cases.

\section{Conclusion}

Our model explores a novel aspect of the evolution of phenological asynchrony between a species and its resource: the effect of landscape heterogeneity. The model was inspired by certain species of winter-resident parids, however we note that the prior residence effects central to the model have been observed in a wide range of taxa, from insects (Waage 1988) to mammals (Haley 1994), and that breeding phenology influences competitive ability in other species (e.g. salmon, Huntingford and Leaniz 1997). Depending upon the particular scenario, our model predicted that either an asymmetric or a more insular pattern of recruit flow between habitat types could occur, which will influence gene flow between habitat types. Therefore we suggest that the consequences of carryover effects on sourcesink dynamics and local adaptation are areas for future work. 
Acknowledgements The authors thank Anne Charmantier, Jacques Blondel, and Jan- $\AA$ ke Nilsson for helpful discussions, Ryan Chisholm for comments on the manuscript, both reviewers for detailed comments and criticisms, and gratefully acknowledge support from: the research environment BECC (Biodiversity and Ecosystem services in a Changing Climate); the Swedish Research Council (2012-3620 to NJ, 201500302 to JJ); Marie Sklodowska Curie Actions, Cofund, Project INCA (600398 to JJ); and the Swedish Research Council Formas (2015-839 to JJ). The authors have no conflicts of interest.

Open Access This article is distributed under the terms of the Creative Commons Attribution 4.0 International License (http://creativecommons.org/licenses/by/4.0/), which permits unrestricted use, distribution, and reproduction in any medium, provided you give appropriate credit to the original author(s) and the source, provide a link to the Creative Commons license, and indicate if changes were made.

\section{References}

Alatalo RV, Lundberg A, Glynn C (1986) Female pied flycatchers choose territory quality and not male characteristics. Nature 323:152-153

Arcese P, Smith J (1985) Phenotypic correlates and ecological consequences of dominance in song sparrows. J Anim Ecol 54:817-830

Baker MC (1978) Flocking and feeding in the great tit Parus major-an important consideration. Am Nat 112:779-781

Blondel J (2007) Coping with habitat heterogeneity: the story of Mediterranean blue tits. J Ornithol 148:3-15

Blondel J, Dias PC, Maistre M, Perret P (1993) Habitat heterogeneity and life-history variation of Mediterranean blue tits (Parus caeruleus). Auk 110:511-520

Both C, Van Asch M, Bijlsma RG, Van Den Burg AB, Visser ME (2009) Climate change and unequal phenological changes across four trophic levels: constraints or adaptations? J Anim Ecol 78:73-83

Braillet C, Charmantier A, Archaux F, Dos Santos A, Perret P, Lambrechts MM (2002) Two blue tit Parus caeruleus populations from Corsica differ in social dominance. J Avian Biol 33:446-450

Brännström Å, Johansson J, von Festenberg N (2013) The hitchhikers guide to adaptive dynamics. Games 4:304-328

Brawn JD, Samson FB (1983) Winter behavior of tufted titmice. Wilson Bull 95:222-232

Broughton RK, Bellamy PE, Hill RA, Hinsley SA (2015) Winter social organisation of Marsh Tits Poecile palustris in Britain. Acta Ornithol 50:11-21

Carrascal LM, Senar JC, Mozetich I, Uribe F, Domenech J (1998) Interactions among environmental stress, body condition, nutritional status, and dominance in great tits. Auk 115:727-738

Charmantier A, Doutrelant C, Dubuc-Messier G, Fargevieille A, Szulkin M (2016) Mediterranean blue tits as a case study of local adaptation. Evolut Appl 9:135-152

Cholewa M, Wesołowski T (2011) Nestling food of European hole-nesting passerines: do we know enough to test the adaptive hypotheses on breeding seasons? Acta Ornithol 46:105-116

Cristol DA, Nolan V Jr, Ketterson ED (1990) Effect of prior residence on dominance status of dark-eyed juncos, Junco hyemalis. Anim Behav 40:580-586

Davis JM, Stamps JA (2004) The effect of natal experience on habitat preferences. Trends Ecol Evolut 19:411-416

Desrochers A, Hannon SJ, Nordin KE (1988) Winter survival and territory acquisition in a northern population of Black-capped Chickadees. Auk 105:727-736

Dias PC, Blondel J (1996) Local specialization and maladaptation in the Mediterranean blue tit (Parus caeruleus). Oecologia 107:79-86

Dias P, Verheyen G, Raymond M (1996) Source-sink populations in Mediterranean blue tits: evidence using single-locus minisatellite probes. J Evolut Biol 9:965-978

Dieckmann U, Law R (1996) The dynamical theory of coevolution: a derivation from stochastic ecological processes. J Math Biol 34:579-612

Eden S (1987) Dispersal and competitive ability in the magpie: an experimental study. Anim Behav 35:764-772

Ekman J (1989) Ecology of non-breeding social systems of Parus. Wilson Bull 101:263-288

Ekman JB, Askenmo CE (1984) Social rank and habitat use in willow tit groups. Anim Behav 32:508-514

Geritz S, Kisdi E, Meszéna G, Metz J (1999) Evolutionarily singular strategies and the adaptive growth and branching of the evolutionary tree. Evolut Ecol 12:35-57

Grunberger S, Leisler B (1990) Innate and learned components in the habitat selection of coal tits (Parusater). Journal fur Ornithologie 131:460-464 
Haley MP (1994) Resource-holding power asymmetries, the prior residence effect, and reproductive payoffs in male northern elephant seal fights. Behav Ecol Sociobiol 34:427-434

Hay JM (2003) The structure of dominance hierarchies in the paridae: consequences for foraging efficiency and body condition. Ph.D. thesis, Durham University

Hay JM, Evans PR, Ward RM, Hamer KC (2004) Poor nutritional condition as a consequence of high dominance status in the Coal Tit Parus ater. Ibis 146:103-107

Hogstad O (1987) Social rank in winter flocks of willow tits Parus montanus. Ibis 129:1-9

Hogstad O (1988) Social rank and antipredator behaviour of willow tits Parus montanus in winter flocks. Ibis 130:45-56

Hogstad O (1989) Social organization and dominance behavior in some Parus species. Wilson Bull 101:254-262

Hogstad O (1999) Territory acquisition during winter by juvenile willow tits Parus montanus. Ibis 141:615-620

Holt RD (1996) Adaptive evolution in source-sink environments: direct and indirect effects of densitydependence on niche evolution. Oikos 75:182-192

Huntingford F, Leaniz CG (1997) Social dominance, prior residence and the acquisition of profitable feeding sites in juvenile Atlantic salmon. J Fish Biol 51:1009-1014

Ives AR, Andow D (2002) Evolution of resistance to Bt crops: directional selection in structured environments. Ecol Lett 5:792-801

Johansson J, Jonzén N (2012) Game theory sheds new light on ecological responses to current climate change when phenology is historically mismatched. Ecol Lett 15:881-888

Johansson J, Smallegange IM, Jonzén N (2012) An eco-evolutionary model for demographic and phenological responses in migratory birds. Biology 1:639-657

Johansson J, Smith HG, Jonzén N (2014) Adaptation of reproductive phenology to climate change with ecological feedback via dominance hierarchies. J Anim Ecol 83:440-449

Johansson J, Kristensen NP, Nilsson JÅ, Jonzén N (2015) The eco-evolutionary consequences of interspecific phenological asynchrony-a theoretical perspective. Oikos 124:102-112

Jonzén N, Hedenström A, Lundberg P (2007) Climate change and the optimal arrival of migratory birds. Proc R Soc B 274:269-274

Källander H, Hasselquist D, Hedenström A, Nord A, Smith HG, Nilsson JÅ (2017) Variation in laying date in relation to spring temperature in three species of tits (Paridae) and pied flycatchers Ficedula hypoleuca in southernmost Sweden. J Avian Biol 48:83-90

Kavanagh KD, Haugen TO, Gregersen F, Jernvall J, Vøllestad LA (2010) Contemporary temperaturedriven divergence in a Nordic freshwater fish under conditions commonly thought to hinder adaptation. BMC Evolut Biol 10:1

Kisdi É (2002) Dispersal: risk spreading versus local adaptation. Am Nat 159:579-596

Koivula K, Lahti K, Orell M, Rytkönen S (1993) Prior residency as a key determinant of social dominance in the willow tit (Parus montanus). Behav Ecol Sociobiol 33:283-287

Kokko H (1999) Competition for early arrival in migratory birds. J Anim Ecol 68:940-950

Krebs JR (1982) Territorial defence in the great tit (Parus major): do residents always win? Behav Ecol Sociobiol 11:185-194

Kristensen N, Johansson J, Ripa J, Jonzén N (2015) Phenology of two interdependent traits in migratory birds in response to climate change. Proc R Soc B 282:20150288

Kristensen N, Johansson J, Chisholm R, Smith H, Kokko H (2018) Carryover effects from natal habitat type upon competitive ability lead to trait divergence or source-sink dynamics. Ecol Lett 29:13411352. https://doi.org/10.1111/ele.13100

Lack D (1950) The breeding seasons of European birds. Ibis 92:288-316

Lack D (1954) The natural regulation of animal numbers. The Clarendon Press, Oxford

Lahti K, Koivula K, Orell M, Rytkönen S (1996) Social dominance in free-living Willow Tits Parus montanus: determinants and some implications of hierarchy. Ibis 138:539-544

Lambrechts MM, Blondel J, Hurtrez-Bousses S, Maistre M, Perret P (1997) Adaptive inter-population differences in blue tit life-history traits on Corsica. Evolut Ecol 11:599-612

Leimar O (2009) Multidimensional convergence stability. Evolut Ecol Res 11:191-208

Matthysen E (1990) Nonbreeding social organization in Parus. Curr Ornithol 7:209-249

Maynard Smith J (1979) Game theory and the evolution of behaviour. Proc R Soc B 205:475-488

Nilsson JA (1990) Establishment success of experimentally delayed juvenile marsh tits Parus palustris. Ethology 85:73-79

Nilsson JA (1999) Fitness consequences of timing of reproduction. In: Adams N, Slotow R (eds) Proceedings of the 22nd international ornithological congress, Durban. BirdLife South Africa, Johannesburg, pp 234-247 
Nilsson JA, Smith HG (1988) Effects of dispersal date on winter flock establishment and social dominance in marsh tits Parus palustris. J Anim Ecol 57:917-928

O’Connor CM, Norris DR, Crossin GT, Cooke SJ (2014) Biological carryover effects: linking common concepts and mechanisms in ecology and evolution. Ecosphere 5:1-11

Pakanen VM, Orell M, Vatka E, Rytkönen S, Broggi J (2016) Different ultimate factors define timing of breeding in two related species. PLoS ONE 11:e0162643

Perrins C (1970) The timing of birds breeding seasons. Ibis 112:242-255

Pulliam HR (1988) Sources, sinks, and population regulation. Am Nat 132:652-661

Saitou T (1979) Ecological study of social organization in the great tit, Parus major L., 2: formation of the basic flocks. J Yamashina Inst Ornithol 9:137-148

Sandell M, Smith HG (1991) Dominance, prior occupancy, and winter residency in the great tit (Parus major). Behav Ecol Sociobiol 29:147-152

Sanz J (2001) Experimentally increased insectivorous bird density results in a reduction of caterpillar density and leaf damage to Pyrenean oak. Ecol Res 16:387-394

Shafer A, Wolf JB (2013) Widespread evidence for incipient ecological speciation: a meta-analysis of isolation-by-ecology. Ecol Lett 16:940-950

Snell-Rood EC, Cristol DA (2005) Prior residence influences contest outcome in flocks of non-breeding birds. Ethology 111:441-454

Teplitsky C, Robinson MR, Merilä J (2014) Evolutionary potential and constraints in wild populations. In: Charmantier A, Garant Loeske LEB, Kruuk EB (eds) Quantitative genetics in the wild. Oxford University Press, Oxford, pp 190-207

Vatka E, Orell M, Rytkönen S (2011) Warming climate advances breeding and improves synchrony of food demand and food availability in a boreal passerine. Glob Change Biol 17:3002-3009

Vatka E, Orell M, Rytkönen S (2016) The relevance of food peak architecture in trophic interactions. Glob Change Biol 22:1585-1594

Veen T, Sheldon B, Weissing F, Visser M, Qvarnström A, Sætre G (2010) Temporal differences in food abundance promote coexistence between two congeneric passerines. Oecologia 162:873-884

Velando A (2000) The importance of hatching date for dominance in young shags. Anim Behav 60:181-185

Verhulst S, Perrins C, Riddington R (1997) Natal dispersal of great tits in a patchy environment. Ecology 78:864-872

Visser ME, Both C (2005) Shifts in phenology due to global climate change: the need for a yardstick. Proc R Soc B 272:2561-2569

Visser M, Van Noordwijk A, Tinbergen J, Lessells C (1998) Warmer springs lead to mistimed reproduction in great tits (Parus major). Proc R Soc Lond B Biol Sci 265:1867-1870

Waage JK (1988) Confusion over residency and the escalation of damselfly territorial disputes. Anim Behav 36:586-595

Wesołowski T (1998) Timing and synchronisation of breeding in a Marsh Tit Parus palustris population from a primaeval forest. Ardea 86:89-100

Wesołowski T, Rowiński P (2014) Do Blue Tits Cyanistes caeruleus synchronize reproduction with caterpillar peaks in a primeval forest? Bird Study 61:231-245

Yasukawa K, Bick EI (1983) Dominance hierarchies in dark-eyed juncos (Junco hyemalis): A test of a gametheory model. Anim Behav 31:439-448

\section{Affiliations}

\section{Nadiah Pardede Kristensen ${ }^{1,3}$ (D) . Jacob Johansson ${ }^{1} \cdot$ Niclas Jonzén ${ }^{1}$. Henrik G. Smith ${ }^{1,2}$}

1 Department of Biology, Lund University, Lund, Sweden

2 Centre of Environmental and Climate Research, Lund University, Lund, Sweden

3 Department of Biological Sciences, National University of Singapore, Singapore, Singapore 